\title{
1 Confidence in soil carbon predictions undermined by uncertainties in 2 observations and model parameterisation
}

3 Zhongkui Luo ${ }^{1}$, Enli Wang ${ }^{1}$, Quanxi Shao ${ }^{2}$, Mark K. Conyers ${ }^{3}$, Deli Liu ${ }^{3}$

$4 \quad{ }^{1}$ CSIRO Agriculture Flagship, GPO Box 1666, Canberra, ACT 2601, Australia

$5 \quad{ }^{2}$ CSIRO Digital Productivity \& Services Flagship, Private Bag 5, Wembley, WA 6913,

6 Australia

$7 \quad{ }^{3}$ NSW Department of Primary Industries, Wagga Wagga Agricultural Institute, PMB, Wagga

8 Wagga, NSW 2650, Australia.

9 Correspondence to: Zhongkui Luo (zhongkui.luo@ csiro.au) and Enli Wang

10 (Enli.Wang@csiro.au)

Abstract

Soil carbon (C) responds quickly and feedbacks significantly to environmental changes such as climate warming and agricultural management. Soil C modelling is the only reasonable approach available for predicting soil $\mathrm{C}$ dynamics under future conditions of environmental changes, and soil $\mathrm{C}$ models are usually constrained by the average of observations. However, model constraining is sensitive to the observed data, and the consequence of using observed averages on $\mathrm{C}$ predictions has rarely been studied. Using long-term soil organic $\mathrm{C}$ datasets from an agricultural field experiment, we constrained a process-based model using the average of observations or by taking into account the variation in observations to predict soil $\mathrm{C}$ dynamics. We found that uncertainties in soil $\mathrm{C}$ predictions were masked if ignoring the uncertainties in observations (i.e., using the average of observations to constrain model), if uncertainties in model parameterisation were not explicitly quantified. However, if uncertainties in model parameterisation had been considered, further considering uncertainties in observations had negligible effect on 
uncertainties in SOC predictions. The results suggest that uncertainties induced by model parameterisation are larger than that induced by observations. Precise observations representing the real spatial pattern of SOC at the studied domain, and model structure improvement and constrained space of parameters will benefit reducing uncertainties in soil $\mathrm{C}$ predictions. The results also highlight some areas on which future $\mathrm{C}$ model development and software implementations should focus to reliably infer soil $\mathrm{C}$ dynamics.

Keywords: carbon cycle, carbon sequestration, measurement uncertainty, model optimisation, prediction uncertainty

\section{Introduction}

Integrated approaches such as process-based mechanistic models are increasingly use to systematically explain, explore and predict responses of natural and human-managed systems to environmental changes (Holzworth et al., 2015, Laniak et al., 2013). Under changing environmental conditions such as global warming and land management change, soil carbon (C) dynamics is particularly important as its core role in determining $\mathrm{C}$ and nutrient cycling in terrestrial ecosystems and the relevant environmental footprints. Soil C models are the only reasonable approach available for assessing soil $\mathrm{C}$ dynamics across spatiotemporal scales and for understanding mechanisms underpinning soil $\mathrm{C}$ stability under various environments (Friedlingstein et al., 2006, Thornton et al., 2007). In order to use these models to design effective management strategies, it is vital to understand the confidence level in model performance (Bennett et al., 2013, Kelly (Letcher) et al., 2013). A number of studies have recognised that reliability of model predictions must be carefully assessed due to uncertainties in model inputs, model parameters and structure, and scaling of model outputs etc. (Clifford et al., 2014, He et al., 2014, Luo et al., 2013, Ogle et al., 2010, Post et al., 2008, Xia et al., 2013). An additional source of uncertainty comes from the spatial variability in soil C measurements that are used to constrain soil C model, and has not been explicitly 
quantified in current soil $\mathrm{C}$ modelling.

Most soil C models divide soil C into several conceptual pools with different decomposability, and simulate decomposition of each pool by first-order kinetics (Smith et $a l ., 1997)$. Some of the pools cannot be directly measured and there is no agreed process to initialise these pools with bulked measurements of total soil C. As a result, derivation of the decomposition rate of those pools is constrained by local observed data of total SOC. The common practice is to derive a single set of model parameters that enables a good match between simulated soil $\mathrm{C}$ and the average of measured soil $\mathrm{C}$ (based on different replicates) at given time. Such constrained models are then used to predict possible soil $\mathrm{C}$ changes under different management practices across environments (Grace et al., 2006, Li et al., 2003, Lugato et al., 2014, Todd-Brown et al., 2014).

Such predictions are subject to unknown uncertainties. Firstly, uncertainty in initialisation of soil $\mathrm{C}$ pools interacts with uncertainty in derived decomposition rates. For example, similar model performance can be achieved either by optimising decomposition rates or by partitioning total soil $\mathrm{C}$ to different conceptual pools with different decomposition rates. Secondly, inaccuracy and/or variability in bulked measurements of total soil C further impact on initialisation and parameterisation of the model. As a result, model initialisation and parameterisation become very sensitive to the data that are used for model constraining (Hararuk et al., 2014, Juston et al., 2010, Keenan et al., 2012, Xenakis et al., 2008;Ogle et al., 2010, Weng \& Luo, 2011). Even at the field scale, great spatial variability exists in soil properties including soil C (Cambardella et al., 1994). For example, Zhou et al. (2008) demonstrated that soil $\mathrm{C}$ varied strongly spatially and its spatial autocorrelation only occurs in $\sim 2 \mathrm{~m}$ of distance in a grazed grassland. Todd-Brown et al. (2013) have suggested that uncertainty in bulked measurements of soil $\mathrm{C}$ content must be integrated with errors involved in extrapolating data from individual soil profiles to the regional scale. This spatial variability 
makes it difficult, if not impossible, to derive the real estimate of average soil $\mathrm{C}$ for model initialisation and/or parameterisation based on limited samples.

To date, however, most of studies focused on uncertainty in model inputs in terms of limited availability of a specific data source (e.g., edaphic characteristics at higher resolution, and information on land use and management) that is needed to initialise and/or parameterise model (Falloon et al., 2011, Luo et al., 2013). Some other studies also addressed the effect of data derived from different environments on model parameterisation thereby model outputs (Hararuk et al., 2014, Juston et al., 2010). In this study, we used a process-based biophysical model, the Agriculture Production Systems sIMulator APSIM (Holzworth et al., 2014, Keating et al., 2003), together with a long-term soil organic C observational (measured 20 times during a 25-year experiment) dataset, to quantify: 1) the potential uncertainty in soil C predictions caused by model initialisation and parameterisation , and 2) the additional uncertainty caused by variation in soil $\mathrm{C}$ measurements that are used for model initialisation and parameterisation. For the latter, variation in replicates for each of the 20 observations during a 25-year agricultural experiment were investigated when using the data to constrain the model. The results can provide insights into collection of effective data sets for model constraining and development of next generation models.

\section{Materials and Methods}

\subsection{Study site and data source}

Field experimental data collected by the Wagga Wagga Agricultural Institute of NSW Department of Primary Industries was used in this study. The experimental site was located at the Wagga Wagga, New South Wales, Australia $\left(35.11^{\circ} \mathrm{S}, 147.37^{\circ} \mathrm{E}\right)$. It has a temperate climate with uniform rainfall distribution across the year. Mean annual temperature was $15.9^{\circ} \mathrm{C}$ and mean annual rainfall was $538 \mathrm{~mm}$. The soil is a chromic luvisol, and the site was 
maintained as an annual pasture for 19 years from 1960 to 1978, except for a crop of lupins (Lupinus Angustifolius) in 1975 and oats (Avena Sativa) in 1976. The surface $10 \mathrm{~cm}$ soil was a clay loam with $29 \%$ clay, $15 \%$ silt and $\mathrm{pH} 4.9$ in 1979. Data collected under two treatments, continuous wheat with (100 $\mathrm{kg} \mathrm{N} \mathrm{ha}^{-1} \mathrm{yr}^{-1}$, N100) and without nitrogen (N0) fertilizer application, were used for this study. In both treatments, residue was burned, and soil organic C content (\%) in the $0-10 \mathrm{~cm}$ soil layer was observed 20 times for each treatment from 1979 to 2004, each time with five or up to 12 replicates for each observation (Fig. 1). Soil bulk density was also measured along with the measurement of soil $\mathrm{C}$ content, and they were used to calculate soil $\mathrm{C}$ stock $\left(\mathrm{t} \mathrm{ha}^{-1}\right)$. More detailed information on experimental design, soil sampling strategy, land use, soil conditions, management and observations for this experiment can be found in Heenan et al. $(2004,1995)$.

\subsection{The APSIM model}

The Agricultural Production Systems sIMulator APSIM (Holzworth et al, 2014; Keating et al., 2003) was used to simulate observed soil $\mathrm{C}$ dynamics in the two treatments (N0 vs N100). The APSIM model is a process-based bio-physical model designed to study productivity, nutrient cycling and environmental impacts of farming systems as influenced by climate variability and management interventions. The ability of APSIM to simulate soil C and soil nitrogen $(\mathrm{N})$ dynamics has been verified under various cropping systems and agricultural management (Luo et al., 2011, Probert et al., 1998). The model divides soil C into six pools and simulates each pool as a first-order process with the rate constants being modified by factors involving soil temperature, moisture and nutrient availability in the soil layer, which is similar to other widely used soil C models such as Century (Parton et al., 1987) and RothC (Jenkinson, 1990). A detailed conceptual diagram of the model for simulating soil C dynamics is presented by Probert et al. (1998) and Luo et al. (2014). 
APSIM runs on a daily time-step and needs daily weather data as inputs, including

radiation, maximum and minimum temperatures, and rainfall. Other required soil parameters includes soil $\mathrm{C}$ content, $\mathrm{C}$ to $\mathrm{N}$ ratio of the bulk soil, soil bulk density, hydraulic parameters, initial soil water and nutrient conditions $\left(\mathrm{NO}_{3}{ }^{-}\right.$and $\left.\mathrm{NH}_{4}{ }^{+}\right)$in each soil layer. All these data and the relevant model initialisation and parameterisation processes were adopted from two former APSIM simulation studies using the same dataset by Luo et al. $(2014,2011)$.

\subsection{Constraining the APSIM model}

The model was constrained with observed soil C data from the N0 and N100 treatments. Model parameters were derived through constraining model simulations against observed data from both treatments. Two parameters were targeted: the potential decomposition rate of humic $\mathrm{C}$ pool (rdhum) and the amount of recalcitrant $\mathrm{C}$ pool in total soil C (finert). The two parameters directly control the turnover time and decomposability of soil C. Sensitivity analysis of eight main parameters that directly link to C decomposition has indicated that these two parameters were the two most important parameters to which soil C dynamics are most sensitive in the APSIM model (Luo et al., 2015).

Three optimisation strategies were used to optimise the model by minimising the combined rooted mean of squared errors (RMSE, i.e., the objective function for optimise and DEoptim, see below) between simulated and observed soil C under the two treatments. That is, 1) optimise finert only (Opt1), 2) optimise rdhum only (Opt2), and 3) optimise rdhum and finert synchronously (Opt3). We used the similar Bayesian approach of Yeluripati et al. (2009) to derive the posterior distributions of the two parameters (finert and/or $r$ dhum). Both parameters were bounded within a range that is biologically and physically possible, therefore eliminating solutions in conflict with prior knowledge. For $r d h u m$, we assumed that 0.000015 day $^{-1} \leq$ rdhum $\leq 0.0015$ day $^{-1}$ (equivalent to around 2-200 years representing an 
approximate range of turnover time of humic organic C) and was uniformly distributed, representing our prior knowledge. For finert, however, we treated the smallest SOC value $(\min C)$ in the combined dataset under $\mathrm{N} 0$ and $\mathrm{N} 100$ as the upper limit of finert (because the two treatments originated from the same plot and potentially have similar amount of inert C). Thus, prior distribution of finert was a uniform distribution ranging from 0 to $\operatorname{minC}$. For Opt1 and Opt2, the function optimise for single parameter optimisation in the package stats of the scientific computing software R (R Core Team, 2012) was used to find the suitable parameter value. For Opt3, differential evolution algorithm was conducted to optimise rdhum and finert simultaneously using DEoptim function in the package DEoptim of R (Mullen et al., 2009).

\section{Scenario1 - optimising the model using observed average soil C: For model}

optimisation, a common practice is that model parameters are derived by comparing simulated soil $\mathrm{C}$ with the average of measured soil $\mathrm{C}$ (based on different replicates) at given time. We treated this practice as the "business-as-usual" scenario, and the replicates for each of the 20 sets of observations under each treatment were used to calculate the average of observed soil $\mathrm{C}(\bar{x})$. These averages were used to constrain the model using the three optimisation strategies (Opt1, Opt2 and Opt3). For Opt1 (i.e., optimising finert only), rdhum was set to the default value $\left(0.00015 \mathrm{day}^{-1}\right)$ in the model. For Opt2 (i.e., optimising $r d h u m$ only), the optimised finert from Opt1 was used. For Opt1 and Opt2, no uncertainty in the parameters is expected because of the nature of single parameter optimisation. For Opt3 (i.e., optimising finert and rdhum simultaneously), however, similar model performance can be obtained with a number of ensembles of rdhum and finert. Using the observed average soil C $(\bar{x}), 100$ ensembles of the two parameters were generated and represented the uncertainty in model parameters. The joint distributions of rdhum and finer represents the posterior distributions of the parameters inferred by the data. This constraining procedure assumed that $\bar{x}$ represent the true values of soil $\mathrm{C}$ stocks $(\mu)$, and uncertainty in future simulations with 
these derived parameter sets represents the uncertainty caused by model initialisation and parameterisation.

Scenario 2 -optimising the model considering the uncertainty in soil C observations:

In reality, however, there exists large spatial variability in soil C stock even at the field scale. It is difficult to determine the true probability distribution of soil $\mathrm{C}$ and to obtain its statistical characteristics (e.g., mean and variance) using limited replicates. Therefore, estimate of the average $\left(\mu^{*}\right)$ has to be combined with distributional assumptions on soil C stocks (such as normality), and the true distribution of soil C stock has to be inferred using statistical characteristics of the samples. Here, a non-parametric bootstrap approach was used to estimate the distribution of $\mu^{*}$. An estimate of $\mu^{*}$ (i.e., the bootstrap mean) was calculated for the $j^{\text {th }}$ observation based on the corresponding observed average $\left(\bar{x}_{j}\right)$ and a bootstrap resample of residuals $\left(\epsilon_{k}\right)$ :

$$
\mu_{j}^{*}=\frac{\sum_{k=1}^{n_{j}}\left(\bar{x}_{j} \cdot\left(1+\epsilon_{k}\right)\right)}{n_{j}}, j=1,2,3, \ldots, 20
$$

where $\bar{x}_{j}$ is the average of the $n_{j}$ observed replicates for the $j^{\text {th }}$ observation, $\epsilon_{k}$ the relative residual for the $k^{\text {th }}$ replicate which is randomly sampled from the distribution of relative residuals estimated by pooling together the relative residuals of all observations. For any given set of observation (e.g. $j^{\text {th }}$ ), the relative residual was calculated as the difference between the replicate and the average of all replicates (for the $j^{\text {th }}$ observation) divided by that average. This calculation using Eqn (1) not only ensures that the bootstrap samples are not negative (it is impossible for soil $\mathrm{C}$ stock) but also considers the possible soil $\mathrm{C}$ change with time. For each of the 20 observations, a total of 100 estimates of $\mu^{*}$ (i.e., 100 sets of data) were obtained (i.e., 100 bootstraps), representing an empirical bootstrap distribution of the "observable" average soil C for a given set of observation. The word "observable" was used 
hereafter to indicate that all estimates are possible representation of the true average $\mu$. Model constraining using the three optimisation strategies was performed against each set of the 'observable' data to get 100 sets of parameters for the best agreement between simulated and 'observable' soil C through minimising RMSE. For the 100 sets of 'observable' data, a total of $100 \times 100=10,000$ sets of optimised parameter(s) were generated for optimisation strategy Opt3. The 10,000 sets of parameters include the uncertainties induced by model initialisation and parameterisation (as in Scenario 1), as well as those caused by uncertainties in observations.

\subsection{Uncertainty in soil C predictions}

The constrained model was run from the beginning of the experiment (1979) with the corresponding agricultural management in the two treatments (N0 versus N100), together with either 100 or $100 \times 100$ sets of model parameters derived from the two scenarios of model constraining, and continued for a further 100 years (2005-2104). The observed climate data from 1979 to 2013 was used for the corresponding simulation period, and the climate data from 1923 to 2013 was used for the remaining simulation period from 2014 to 2104. Potential future climate change was not considered in this typical study since we focused on uncertainty in soil $\mathrm{C}$ predictions induced by uncertainty in observations and model parameterisation.

For each optimisation strategy, the $95 \%$ confidence interval (CI, i.e., quantiles corresponding to the probability of 0.025 and 0.975 ) of projected soil $\mathrm{C}$ stock was calculated. The percentage uncertainty (PU) was calculated to indicate the uncertainty of projected soil C under the two scenarios of model constraining:

$$
P U=\frac{C I_{u}-C I_{l}}{M} \times 100 \%,
$$

where $M$ is the average of projected soil $\mathrm{C}$ stocks considering uncertainties in observations 
and/or in model initialisation and parameterisation, $C I_{l}$ and $C I_{u}$ are the lower and upper limits of the $95 \%$ CI respectively. For Opt 1 and Opt2 under scenario 1 (i.e., business-as-usual), uncertainty cannot be estimated because they implicitly assumed that there is no uncertainty in observations and in model initialisation and optimisation.

\section{Results}

Averaging replicates of each observation, $\mathrm{C}$ stock in the top $10 \mathrm{~cm}$ soil showed a declining trend in the studied continuous wheat system under both treatments of N0 (no N application) and N100 (100 $\mathrm{kg} \mathrm{N} \mathrm{ha}^{-1} \mathrm{yr}^{-1}$, Fig. 1). This decline could be well captured by the APSIM model when it was constrained with average values of observational data (Scenario 1) using all three optimisation strategies (i.e., Opt1, Opt2 \& Opt3; Fig. 1 and 2). For Opt3, the optimised finert and rdhum were closely and positively associated (Fig. 2A). Various ensembles of finert and rdhum could lead to equally well agreement between simulated and observed soil C stocks, but resulted in very divergent soil $\mathrm{C}$ predictions, i.e. great prediction
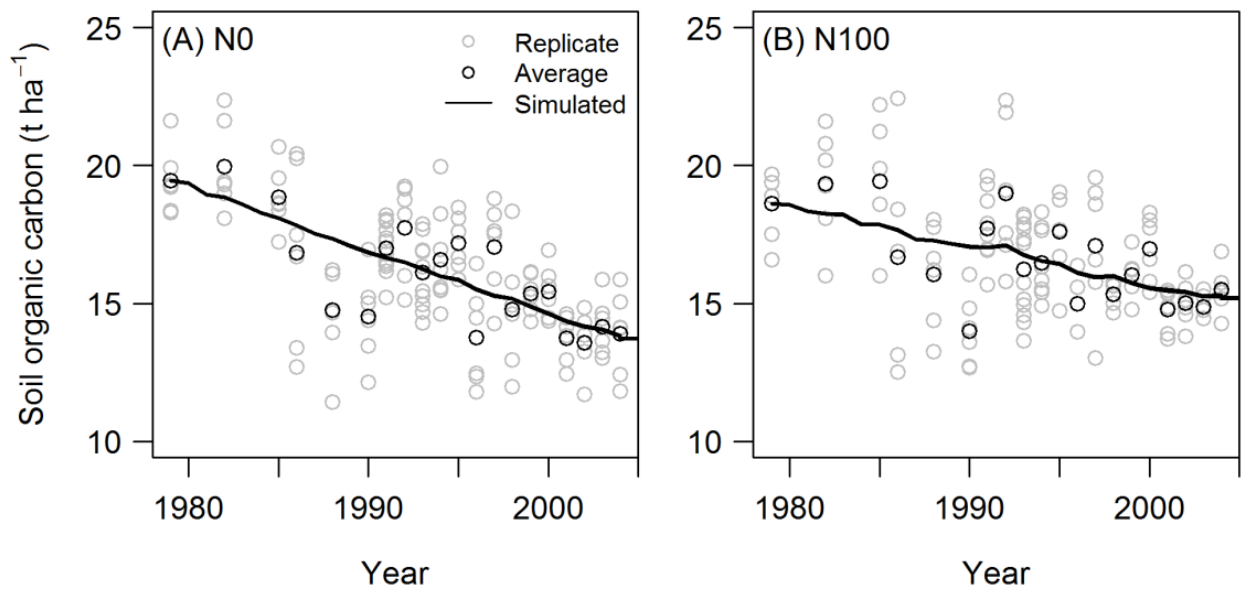

Fig. 1. Simulated and observed soil organic carbon stocks $(0-10 \mathrm{~cm}$ soil layer) under two treatments of N0 (A, no fertilizer application) and N100 (B, $100 \mathrm{~kg} \mathrm{~N} \mathrm{ha}^{-1} \mathrm{yr}^{-1}$ ). The model was constrained by observed average soil C stocks (black circles) through optimising finert (the amount of inert carbon pool) or rdhum (potential decomposition rate of humic organic carbon pool). The simulated soil C stock by separately optimising the two parameters is the same (lines are coincided). Grey circles show the observed replicates. 

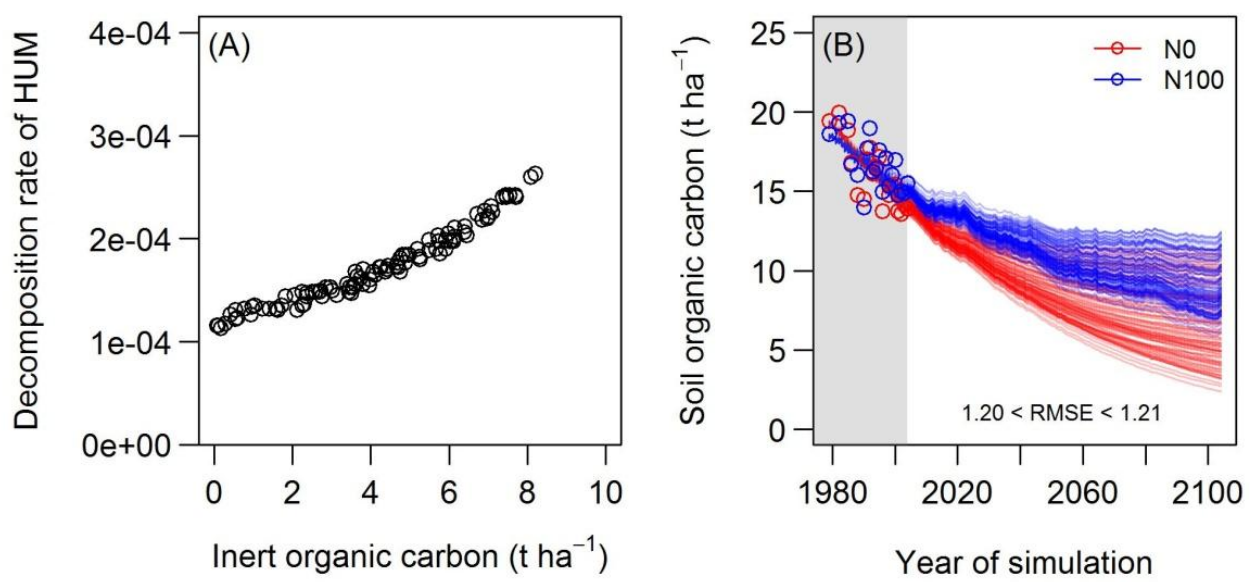

Fig. 2. The distribution and relationship of optimised model parameters (A) and the corresponding simulated soil C dynamics under N0 and N100 treatments (B). The model was constrained by the observed average soil $\mathrm{C}$ stocks under two treatments through optimising finert (the amount of inert carbon pool) and rdhum (potential decomposition rate of humic organic carbon pool) simultaneously. The model constraining period is marked as shading area in (B).The red and blue points are the average of observations, corresponding to the black circles in Fig. 1 for N0 and N100, respectively.
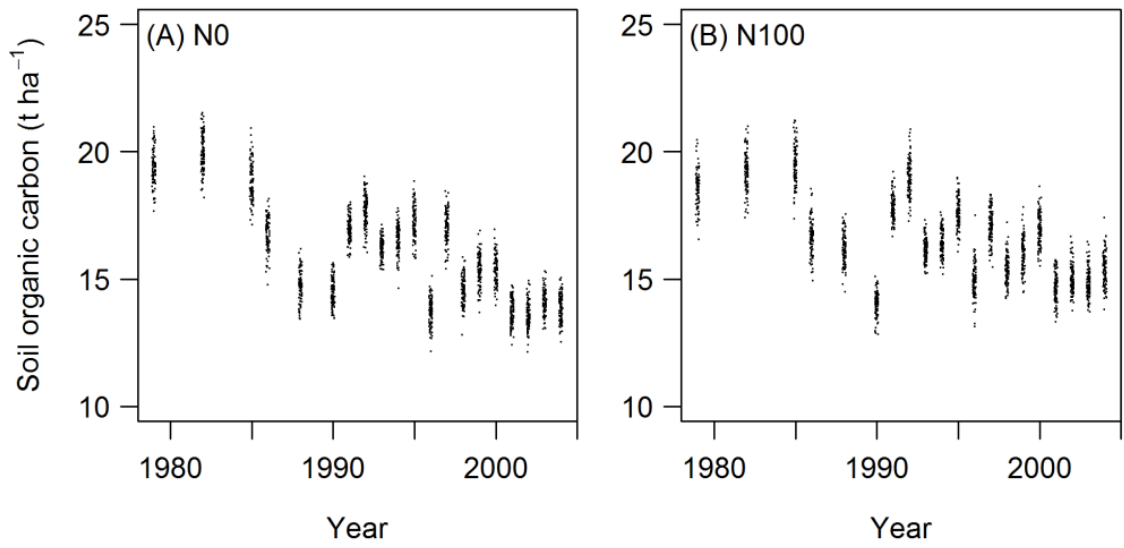

Fig. 3. Uncertainty in observed soil C stocks expressed as the ranges of the 100 empirical bootstrap estimates of "observable" average of soil C stocks for each observation time point under N0 (A) and N100 (B). Any value of the 100 estimates at each observation time point could be used to constrain the model. The year corresponding to the $\mathrm{x}$-axis has been jittered by adding a small random number so that the points do not lie on top of each other. 
“observable" average soil C stock ranged from 17.66 to $20.98 \mathrm{t} \mathrm{ha}^{-1}$ based on estimations of

C stocks (Scenario 2-considering uncertainty in observations) resulted in a wide range of
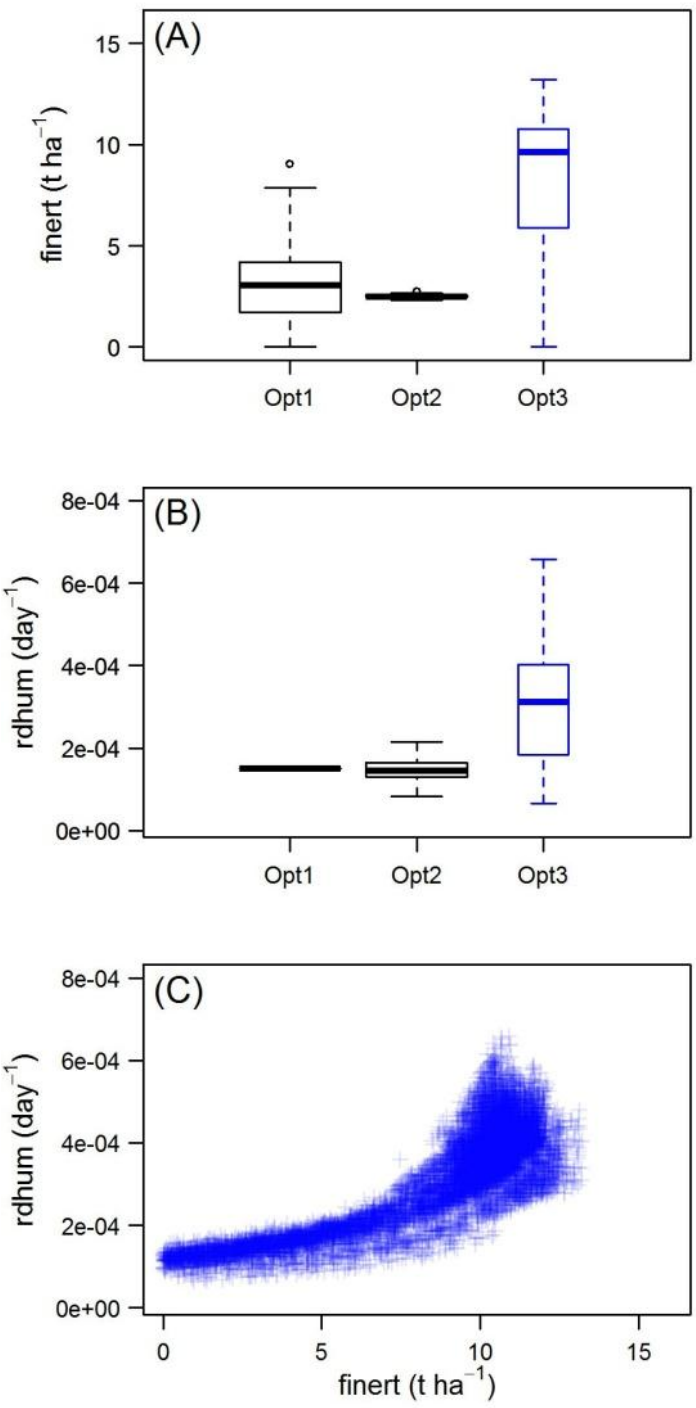

Fig. 4. The distributions and relationship of optimised model parameters. The model was constrained by considering the uncertainty in soil carbon observations. (A) and (B) show the distributions of fitted finert (the amount of inert carbon pool) and rdhum (potential decomposition rate of humic organic carbon pool), respectively, using three optimisation strategies (Opt1, Opt2 and Opt3). (C) shows the relationship between finert and rdhum (10,000 ensembles) using optimisation strategy Opt3. Opt1, optimise finert only; Opt2, optimise rdhum only; Opt3, optimise finert and rdhum simultaneously. 
values for the two parameters (finert and rdhum, Fig. 4) and in soil C simulations (Fig. 5). Fig.

4 shows that the distributions of the two parameters depend on optimisation strategies. Using ranged from 0.000065 to 0.000658 day $^{-1}$ with an average of 0.00030 day $^{-1}$ (Fig. 4B). Both the ranges and averages of finert and rdhum were markedly wider and higher than that using Opt1 and Opt2. Additionally, the optimised finert and rdhum were positively correlated (Fig. 4C), similar to that under Scenario 1 (Fig. 2A).

Under Opt3, using optimised parameter ensembles under Scenario 2 (i.e., considering uncertainty in observations. Fig. 4), the predicted soil C stock was comparable to that using optimised parameter ensembles under Scenario 1 (not considering uncertainty in observations, Fig. 5E and F). Additionally, the averages did not show significant difference $\left(<3 \mathrm{tha}^{-1}\right.$ after 100-year simulations) between the two scenarios (Fig. 5E and F).

In general, percentage uncertainty in soil $\mathrm{C}$ projections increased with the years of prediction (Fig. 5). Under Scenario 2, the percentage uncertainty reached $128 \%$ and $69 \%$ under N0 and N100 respectively using Opt1, 51\% and 56\% respectively using Opt2, after 100-year simulations. Using Opt3, the percentage uncertainty resulting from model initialisation and parameterisation was $122 \%$ and $61 \%$ under $\mathrm{N} 0$ and $\mathrm{N} 100$ respectively under Scenario 1. Further considering the uncertainty in measurement data (Scenario 2) did not further increase the percentage uncertainty in SOC projections, with $97 \%$ and $57 \%$ percentage uncertainty under N0 and N100 respectively (Fig. 5E and F).

\section{Discussion}

Accurate prediction of soil $\mathrm{C}$ dynamics is critical to credibly predict $\mathrm{CO}_{2}$ emissions from soil and thus future climate change. Using comprehensive datasets and approaches for model constraining, results of this study demonstrated that great uncertainty in soil C predictions 

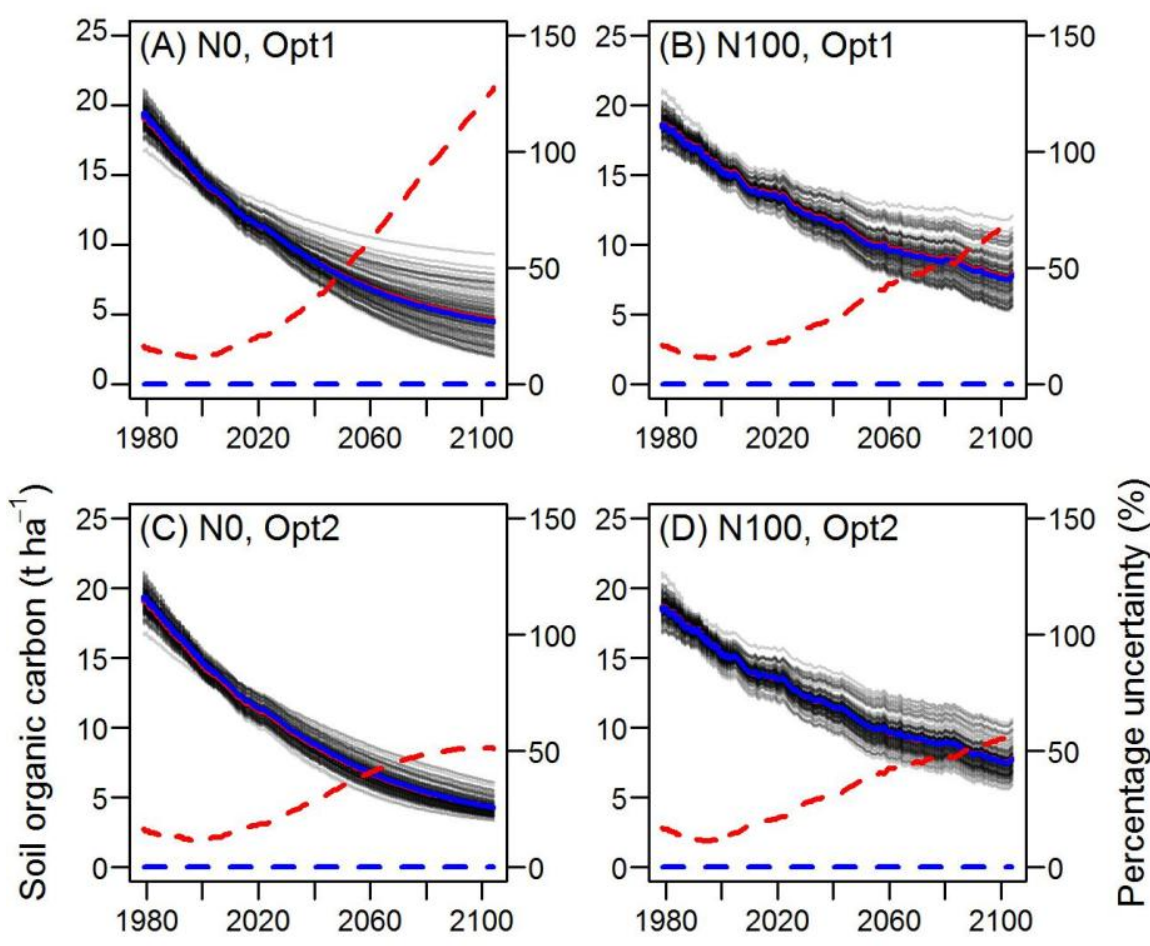

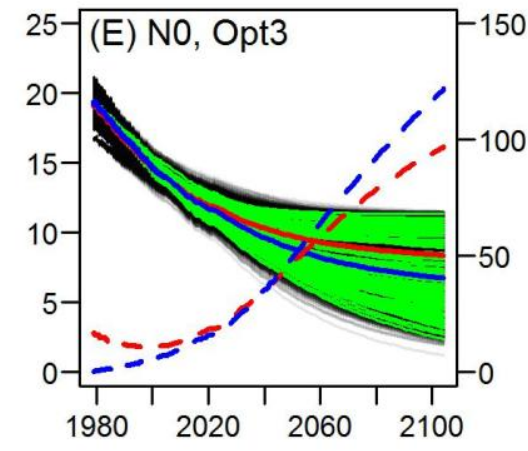

Year of simulation

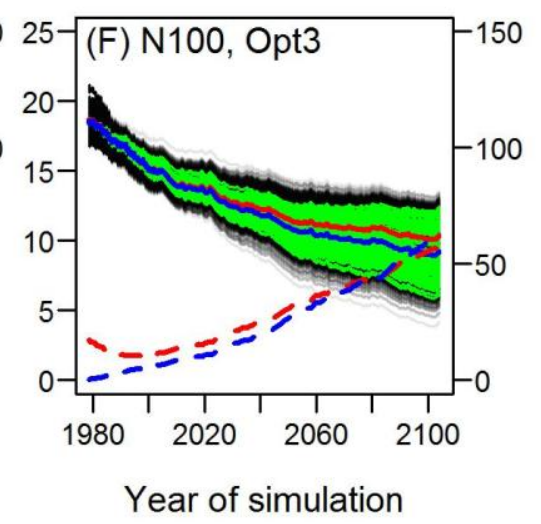

Fig. 5. Uncertainty in soil C predictions using three optimisation strategies (Opt1, Opt2 and Opt3) under two treatments of N0 and N100. The solid blue and red lines show the predicted average soil C stock without (Scenario 1) and with (Scenario 2) consideration of uncertainty in observations, respectively. The grey and blue lines show the bootstrapping simulation results (100 for Opt 1 and Opt2, 10000 for Opt3) under scenario 1 and 2, respectively. In (A), (B), (C) and (D), the blue and red lines are partially coincided. The dashed blue and red lines show the corresponding percentage uncertainty, respectively. Opt1, optimise finert (the amount of inert carbon pool) only; Opt2, optimise rdhum (potential decomposition rate of humic organic carbon pool) only; Opt3, optimise finert and rdhum simultaneously.

using process-based soil $\mathrm{C}$ models could be induced by uncertainties in observations and model parameterisation. If uncertainties in model initialisation/parameterisation were not explicitly considered (Fig. 5 A, B, C and D), traditional model constraining based on measured average soil $\mathrm{C}$ trend could mask uncertainty in soil $\mathrm{C}$ predictions. Constraining the 
model using all available measurement data, including the replicates for each measurement, to define a posterior distribution of model parameters enables the quantification of uncertainty in model predictions. The optimisation procedure like that presented in this study can be incorporated into model and/or software development to facilitate explicit estimate of uncertainties in predictions.

Significant variation in soil C measurement data from the same field forms an additional cause of prediction uncertainty, due to the uncertainty created in model constraining process, which has been ignored in current soil $\mathrm{C}$ modelling in the literature. This additional uncertainty source and its impact on simulation results may vary with agricultural management and the level of soil $\mathrm{C}$ stock in fields. Although the uncertainties were only quantified in a cultivated soil under the studied continuous wheat system in our study, it is expected to be existent or even amplified in other ecosystems because soil C stock in cultivated soils is relatively homogeneous, comparing with undisturbed soils such as forest soil (Conant et al., 2003, Schöning et al., 2006). In this study, however, we did not assess the potential effect of data quantity and quality on uncertainty in model predictions. More studies on how sampling intensity and experimental duration impact the optimisation of model parameters and prediction uncertainty are required. Then, experimental design and sampling strategy can be developed to minimize uncertainty in model predictions resulting from input data for model constraining. In addition, our study focused on soil $\mathrm{C}$ dynamics in the top 10 $\mathrm{cm}$ soil. By considering the different environmental conditions in deep and shallow soil layers (e.g., oxygen availability and fresh C inputs), the pattern of uncertainty in soil C dynamics in deeper layers would be different from that in topper soil layers, which warrants further studies.

It is important to note that the calibrated model parameters showed large uncertainty at our studied typical site (Fig. 2A and 4C). The divergent model parameters finally led to 
divergent model predictions. A more constrained space of model parameters will certainly reduce uncertainty in model predictions (Weng \& Luo, 2011). However, the reality of derived model parameters is difficult to justify without comprehensive understanding of the underlying processes. In process-based models with involvement of multiple collinear parameters, model parameterisation might suffer from the equifinality problem (Luo et al., 2015, Tang \& Zhuang, 2008), i.e., different combinations of model parameters enable the model to equally well simulate observations. In this study, for example, inert $\mathrm{C}$ pool (finert) and potential decomposition rate of humic C pool (rdhum) were positively correlated (Fig. $2 \mathrm{~A}$ and $4 \mathrm{C}$ ), implying that the equifinality problem also exists in the APSIM model. A realistic representation of the interactions and/or feedback between different $\mathrm{C}$ pools and their responses to environmental conditions will be critical for robust model predictions. In addition, however, we acknowledge that this study only focused on two parameters relating to potential decomposition rate and $\mathrm{C}$ pool composition. Essentially, soil $\mathrm{C}$ dynamics is mediated by microbial processes. Microbial $\mathrm{C}$ use efficiency and microbe-mediated pool transformations may change the picture of the estimated uncertainty in soil $\mathrm{C}$ predictions.

If uncertainty in model initialisation and parameterisation had been considered, the results suggested that uncertainty in observations did not markedly increase uncertainty in predictions (the range of soil $\mathrm{C}$ predictions showed in Fig. 5E and F). These results imply that improvements in data availability (during a specific period of observations) for model constraining may not make up the uncertainty resulting from model structure, supporting the suggestion of that the majority of uncertainty in soil $\mathrm{C}$ predictions using process-based model was associated with model structure (He et al., 2014, Ogle et al., 2010). To reduce uncertainty, model structure has to be improved. For example, most of soil C models treat SOM as several conceptual pools and simulate them as a first-order decay process (Smith $e t$ $a l ., 1997)$. This framework should be improved to more explicitly address the heterogeneity 
of soil C composition and their interactions with microbial processes (Schmidt et al., 2011, Sierra et al., 2011). These improvements will benefit reducing uncertainty in model parameters and thus in model predictions.

Our simulations demonstrated the importance of considering observation-induced and model parameterisation-induced uncertainties and their impacts on predicted soil $\mathrm{C}$ dynamics. Although our study only assessed the uncertainty using a specific dataset and the specific APSIM model, the model shares the same framework for simulating soil $\mathrm{C}$ decomposition processes as other soil C and Earth system models (Friedlingstein et al., 2006, Smith et al., 1997). The results suggest that uncertainties in model-based soil C predictions may be masked because of ignoring observation-induced uncertainties in the relevant model applications, if uncertainties in model parameterisation is not explicitly quantified. To reduce observation-induced uncertainties, sophisticated experiment design and sampling strategy are required to obtain more accurate observations such as using consistent microplots for sampling, increasing sample size and applying portable methods for faster analysis of samples (Conant et al., 2003, Don et al., 2007). The prior knowledge of the simulated system (e.g., model parameters and $\mathrm{C}$ pool composition) represented by the model defines the behaviour of the model thereby the space of predictions (Weng \& Luo, 2011). To reduce the parameterisation-induced uncertainties, informative prior distribution of model parameters is required to provide predictions with less uncertainty. However, regardless of data availability and/or model optimisation approaches, the conceptual nature of $\mathrm{C}$ models does not change and the equifinality issue may persistent. We need advanced understanding of microbialsubstrate relationships by considering their linkages with measurable variables (e.g., measurable $\mathrm{C}$ fractions and microbial functional groups).

\section{Acknowledgements}


Funding was provided by the Department of Agriculture (DoA) and the Grain Research and

Development Corporation (GRDC) of Australia. Thanks to Petra Kuhnert and Ryan

Farquharson of CSIRO for their helpful comments on an earlier version of the manuscript.

\section{References}

Bennett ND, Croke BFW, Guariso G et al.(2013) Characterising performance of environmental models. Environmental Modelling \& Software, 40, 1-20.

Cambardella CA, Moorman TB, Novak JM, Parkin TB, Karlen DL, Turco RF, Konopka AE (1994) Field-scale variability of soil properties in Central Iowa soils. Soil Science Society of America Journal, 58, 1501-1511.

Clifford D, Pagendam D, Baldock J et al. (2014) Rethinking soil carbon modelling: a

Conant RT, Smith GR, Paustian K (2003) Spatial Variability of Soil Carbon in Forested and Cultivated Sites. Journal of Environmental Quality, 32, 278-286.

Don A, Schumacher J, Scherer-Lorenzen M, Scholten T, Schulze E-D (2007) Spatial and vertical variation of soil carbon at two grassland sites — Implications for measuring soil carbon stocks. Geoderma, 141, 272-282.

Falloon P, Jones CD, Ades M, Paul K (2011) Direct soil moisture controls of future global soil carbon changes: An important source of uncertainty. Global Biogeochemical Cycles, 25.

Friedlingstein P, Cox P, Betts R et al. (2006) Climate-carbon cycle feedback analysis: Results from the (CMIP)-M-4 model intercomparison. Journal of Climate, 19, 3337-3353.

Grace P, Colunga-Garcia M, Gage S, Robertson GP, Safir G (2006) The Potential Impact of Agricultural Management and Climate Change on Soil Organic Carbon of the North Central Region of the United States. Ecosystems, 9, 816-827. 
Hararuk O, Xia JY, Luo YQ (2014) Evaluation and improvement of a global land model against soil carbon data using a Bayesian Markov chain Monte Carlo method. Journal of Geophysical Research-Biogeosciences, 119, 403-417.

He Y, Yang J, Zhuang Q, McGuire AD, Zhu Q, Liu Y, Teskey RO (2014) Uncertainty in the fate of soil organic carbon: A comparison of three conceptually different decomposition models at a larch plantation, Journal of Geophysical Research-Biogeosciences, 119, 1892 1905.

Heenan DP, Chan KY, Knight PG (2004) Long-term impact of rotation, tillage and stubble management on the loss of soil organic carbon and nitrogen from a Chromic Luvisol. Soil and Tillage Research, 76, 59-68.

Heenan DP, Mcghie WJ, Thomson FM, Chan KY (1995) Decline in soil organic carbon and total nitrogen in relation to tillage, stubble management, and rotation. Australian Journal of Experimental Agriculture, 35, 877-884.

Holzworth DP, Huth NI, deVoil PG, et al. (2014) APSIM-Evolution towards a new generation of agricultural systems simulation. Environmental Modelling \& Software, 62 , 327-350.

Holzworth DP, Snow V, Janssen S, Athanasiadis IN, Donatelli M, Hoogenboom G, White JW, Thorburn P (2015) Agricultural production systems modelling and software: Current status and future prospects. Environmental Modelling \& Software, 72, 276-286.

Jenkinson DS (1990) The turnover of organic carbon and nitrogen in soil. Philosophical Transactions - Royal Society of London, B, 329, 361-368.

Juston J, Andren O, Katterer T, Jansson PE (2010) Uncertainty analyses for calibrating a soil carbon balance model to agricultural field trial data in Sweden and Kenya. Ecological Modelling, 221, 1880-1888. 
Keating BA, Carberry PS, Hammer GL et al. (2003) An overview of APSIM, a model designed for farming systems simulation. European Journal of Agronomy, 18, 267-288.

Kelly (Letcher) RA, Jakeman AJ, Barreteau O et al. (2013) Selecting among five common modelling approaches for integrated environmental assessment and management. Environmental Modelling \& Software 4 47, 159-181.

Keenan TF, Davidson E, Moffat AM, Munger W, Richardson AD (2012) Using model-data fusion to interpret past trends, and quantify uncertainties in future projections, of terrestrial ecosystem carbon cycling. Global Change Biology, 18, 2555-2569.

Laniak FG, Olchin G, Goodall J et al. (2013) Integrated environmental modelling: A vision and roadmap for the future. Environmental Modelling \& Software, 39, 3-23.

Li C, Zhuang Y, Frolking S et al. (2003) Modeling soil organic carbon change in croplands of China. Ecological Applications, 13, 327-336.

Lugato E, Bampa F, Panagos P, Montanarella L, Jones A (2014) Potential carbon sequestration of European arable soils estimated by modelling a comprehensive set of management practices. Global Change Biology, n/a-n/a.

Luo Z, Wang E, Bryan BA, King D, Zhao G, Pan X, Bende-Michl U (2013) Meta-modeling soil organic carbon sequestration potential and its application at regional scale. Ecological Applications, 23, 408-420.

Luo Z, Wang E, Fillery IRP, Macdonald LM, Huth N, Baldock J (2014) Modelling soil carbon and nitrogen dynamics using measurable and conceptual soil organic matter pools in APSIM. Agriculture, Ecosystems \& Environment, 186, 94-104.

Luo Z, Wang E, Sun OJ, Smith CJ, Probert ME (2011) Modeling long-term soil carbon dynamics and sequestration potential in semi-arid agro-ecosystems. Agricultural and Forest Meteorology, 151, 1529-1544. 
Luo Z, Wang E, Zheng H, Baldock J, Sun O, Shao Q (2015) Convergent modeling of past soil organic carbon stocks but divergent projections. Biogeosciences, 12, 4245-4272.

Mullen KM, Ardia D, Gil DL, Windover D, Cline J (2009) DEoptim: An R package for global optimization by differential evolution.

Ogle SM, Breidt FJ, Easter M, Williams S, Killian K, Paustian K (2010) Scale and uncertainty in modeled soil organic carbon stock changes for US croplands using a process-based model. Global Change Biology, 16, 810-822.

Parton WJ, Schimel DS, Cole CV, Ojima DS (1987) Analysis of factors controlling soil organic matter levels in Great Plains grasslands. Soil Science Society of America Journal, 51, 1173-1179.

Post J, Hattermann FF, Krysanova V, Suckow F (2008) Parameter and input data uncertainty estimation for the assessment of long-term soil organic carbon dynamics. Environmental Modelling \& Software, 23, 125-138.

Probert ME, Dimes JP, Keating BA, Dalal RC, Strong WM (1998) APSIM's water and nitrogen modules and simulation of the dynamics of water and nitrogen in fallow systems. Agricultural Systems, 56, 1-28.

R Core Team (2012) R: A language and environment for statistical computing. R Foundation for Statistical Computing, Vienna, Austria. URL http://www.R-project.org/.

Schmidt MWI, Torn MS, Abiven S et al. (2011) Persistence of soil organic matter as an ecosystem property. Nature, 478, 49-56.

Schöning I, Totsche KU, Kögel-Knabner I (2006) Small scale spatial variability of organic carbon stocks in litter and solum of a forested Luvisol. Geoderma, 136, 631-642.

Smith P, Smith J, Powlson D et al. (1997) A comparison of the performance of nine soil organic matter models using datasets from seven long-term experiments. Geoderma, 81, $153-225$. 
Sierra CA, Harmon ME, Perakis SS (2011) Decomposition of heterogeneous organic matter and its long-term stabilization in soils. Ecological Monographs, 81, 619-634.

Tang JY, Zhuang Q (2008) Equifinality in parameterization of process-based biogeochemistry models: A significant uncertainty source to the estimation of regional carbon dynamics. Journal of Geophysical Research: Biogeosciences, 113, G04010.

Thornton PE, Lamarque JF, Rosenbloom NA, Mahowald NM (2007) Influence of carbon- nitrogen cycle coupling on land model response to $\mathrm{CO}_{2}$ fertilization and climate variability. Global Biogeochemical Cycles, 21.

Todd-Brown KEO, Randerson JT, Hopkins F et al. (2014) Changes in soil organic carbon storage predicted by Earth system models during the 21st century. Biogeosciences, 11, 2341-2356.

Todd-Brown KEO, Randerson JT, Post WM, Hoffman FM, Tarnocai C, Schuur EaG, Allison SD (2013) Causes of variation in soil carbon simulations from CMIP5 Earth system models and comparison with observations. Biogeosciences, 10, 1717-1736.

Weng E, Luo Y (2011) Relative information contributions of model vs. data to short- and long-term forecasts of forest carbon dynamics. Ecological Applications, 21, 1490-1505.

Xenakis G, Ray D, Mencuccini M (2008) Sensitivity and uncertainty analysis from a coupled 3-PG and soil organic matter decomposition model. Ecological Modelling, 219, 1-16.

Xia J, Luo Y, Wang Y-P, Hararuk O (2013) Traceable components of terrestrial carbon storage capacity in biogeochemical models. Global Change Biology, 19, 2104-2116.

Yeluripati JB, van Oijen M, Wattenbach M, Neftel A, Ammann A, Parton WJ, Smith P (2009) Bayesian calibration as a tool for initialising the carbon pools of dynamic soil models. Soil Biology \& Biochemistry, 41, 2579-2583. 
462 Zhang XS, Sahajpal R, Manowitz DH et al. (2014) Multi-scale geospatial agroecosystem 463 modeling: A case study on the influence of soil data resolution on carbon budget estimates.

$464 \quad$ Science of the Total Environment, 479, 138-150.

465 Zhou Z, Sun O, Luo Z, Jin H, Chen Q, Han X (2008) Variation in small-scale spatial 466 heterogeneity of soil properties and vegetation with different land use in semiarid 467 grassland ecosystem. Plant and Soil, 310, 103-112.

468 Zimmermann M, Leifeld J, Schmidt M, Smith P, Fuhrer J (2007) Measured soil organic 469 matter fractions can be related to pools in the RothC model. European Journal of Soil $470 \quad$ Science, 58, 658-667. 